\title{
Hydrogen Sensing Behavior of Pt-coated Mesoporous Anodic Titania
}

\author{
Mohammad A. Hashemian, Eduard G. Karpov* \\ University of Illinois at Chicago, 842 W Taylor St, Chicago, IL 60607
}

\begin{abstract}
We report on excellent hydrogen sensing properties of a $\mathrm{Pt} / \mathrm{TiO}_{2}$ system based on mesoporous titania grown by plasma electrolytic oxidation of a Ti metal substrate. The Pt phase is deposited onto the titania surface as an electrically continuous $\mathrm{Pt}$ nanomesh layer with an e-beam process. Resistive sensor response between the $\mathrm{Pt}$ and $\mathrm{Ti}$ terminals of the resultant structure is studied at room temperature for different partial pressures of $\mathrm{H}_{2}$ gas (0.003-3 Torr) and different source voltages (0.5-2.0 V). A maximum resistance effect, reaching four orders of the magnitude for 3 Torr $\mathrm{H}_{2}$ in 160 Torr $\mathrm{O}_{2}$ is obtained at the bias voltage $1.4 \mathrm{~V}$, and a strong effect is detected for only 0.003 Torr, or $20 \mathrm{ppm} \mathrm{H}_{2}$ concentration. For voltages in the range 1.0-1.4 V, electrical conductance of the sample is about a linear function of the $\mathrm{H}_{2}$ partial pressure in the gas phase. Influence of the background atmosphere $\left(\mathrm{O}_{2}, \mathrm{~N}_{2}\right.$ and vacuum $)$ and the effect of bias reversal were investigated also, leading to a conclusion that the sensing mechanism can be related to ionic transport in the $\mathrm{TiO}_{2}$ layer.
\end{abstract}

Keywords: nanostructures; oxides; semiconductors; chemisorption; electrical conductivity; transport properties

\section{Introduction}

Due to volatility and flammability of hydrogen gas, a small leakage of hydrogencontaining gases could lead to disastrous consequences. In the recent years, many groups have reported hydrogen sensors with different mechanisms and structures [1-6]. Fedtke

* Corresponding author; Email: ekarpov@uic.edu 
et al. [7] reported electrical and optical changes of thin palladium layer $(40 \mathrm{~nm})$ during the hydrogen adsorption. This sensor showed a good behavior up to $4 \%$ hydrogen in nitrogen. Many groups have reported that metal-semiconductor (MS) Schottky diodes work well as hydrogen sensors [8-10]. Platinum or palladium Schottky diodes based on $n$-type GaN semiconductor revealed significant changes in the electrical characteristic of the sensor upon exposure of hydrogen in Ar or air mixture at room [11] and elevated temperature [12]. Metal-insulator-semiconductor (MIS) Schottky diodes, $\mathrm{Pt} / \mathrm{SiO}_{2} / \mathrm{GaN}$, has been studied over a wide range of temperatures in the normal air atmosphere which demonstrated high sensitivity and a fast response time [13].

$\mathrm{TiO}_{2}$ nanotubes and nanoporous structures have also been studied as hydrogen sensors, showing reversible responses in both air and $\mathrm{N}_{2}$ atmospheres [14-20]. Shimizu et al. [18] outlined the important factors affecting the $\mathrm{H}_{2}$ sensing performance of anodically oxidized $\mathrm{TiO}_{2}$ films, including film morphology, oxidation temperature and electrode materials. The influence of nanotube diameters on the resistance variation of the $\mathrm{TiO}_{2}$ has been tested and a three order of magnitude resistance variation was observed with exposure of $100 \mathrm{ppm}$ hydrogen to $\mathrm{N}_{2}$ ambient [20]. For higher concentration of hydrogen (500 ppm), a four order of magnitude change has been reported. In the previous work, the sensitivity of $\mathrm{TiO}_{2}$ sensor has been studied at various operating temperatures, ranging from $250^{\circ} \mathrm{C}$ to $450^{\circ} \mathrm{C}[21]$.

In this work, we discuss hydrogen sensing properties and mechanisms of a $\mathrm{Pt} / \mathrm{TiO}_{2} / \mathrm{Ti}$ type device based on anodically grown mesoporous titania. The device is simple to fabricate and it demonstrates extreme changes in its electrical resistance due to hydrogen exposure at room temperature. Here, the $\mathrm{Pt}$ catalyst was finely dispersed as an electrically continuous nanometer thickness mesh supported by the $\mathrm{TiO}_{2}$ layer, and the anodized Ti metal substrate served as a base support and back contact, see Figure 1. Dependence of response characteristics on the source voltage is discussed. In order to understand basic mechanisms of the observed sensing performance, the experiments have been carried out in vacuum, oxygen and nitrogen gases at 160 Torr, and at bias reversal conditions. Hydrogen sensing behavior of this system is demonstrated, showing remarkable responses down to 0.003 Torr of $\mathrm{H}_{2}$ partial pressure (20 ppm). 


\section{Sample Preparation and Experimental Setup}

In order to prepare samples with a $\mathrm{Pt} / \mathrm{TiO}_{2}$ interface based on mesoporous titania, a $36 \times 12 \times 0.5 \mathrm{~mm}^{3}$ strip of standard (ASTM B265) 0.989 pure Ti metal was inserted in an aqueous $3 \mathrm{M} \mathrm{H}_{2} \mathrm{SO}_{4}$ solution and anodically oxidized at a current density of $93.2 \mathrm{~mA} / \mathrm{cm}^{2}$ for $3 \mathrm{~min}$ at room temperature until the anode potential reached $155 \mathrm{~V}$. Measured thickness of the resultant $\mathrm{TiO}_{2}$ was 10-11 $\mu \mathrm{m}$. In the next step, a Pt layer of $15 \mathrm{~nm}$ thickness was obtained by sputtering of 0.9995 pure Pt through a $34 \times 10 \mathrm{~mm}^{2}$ mask on top of the porous $\mathrm{TiO}_{2}$ surface via a wide-angle PVD in $10^{-7}$ Torr vacuum at the rate 0.02 $\mathrm{nm} / \mathrm{s}$. Finally, in order to complete the electrical contact of the structure, an SEM grade $\mathrm{Ag}$ paste was applied to attach two $\mathrm{Ag}$ wires $(0.5 \mathrm{~mm}$ diameter $)$ to the two opposite ends of the Pt surface. These fabrication steps are shown schematically in Fig. 1(a). XRD analysis data for the bare $\mathrm{TiO}_{2}$ surface, and FESEM imaging of the Pt-coated $\mathrm{TiO}_{2}$ surface are shown in Figs. 1(b) and 1(c), respectively. An RTD sensor of dimension $2 \times 2 \times 0.8 \mathrm{~mm}^{3}$ (Omega F2020-100) was attached in the middle of Pt surface for surface temperature monitoring. The sample was mounted inside a stainless steel $4.5 \mathrm{~L}$ vacuum chamber using a copper clamp attached to one of the pins of an electrical feedthrough flange.

Prior to the hydrogen sensing measurements, the sample surface was activated by oxyhydrogen reactions. The activation procedure has been described elsewhere [22]. Upon completion of the activation process, a repeatable baseline for resistance reading was obtained by exposing the sample to 160 Torr atmosphere of pure $\mathrm{O}_{2}$ during $65 \mathrm{~h}$, while a constant source voltage was kept applied to the sample. The resistance data recording started after $41 \mathrm{~h}$ of the exposure. Such a long pre-exposure with the source voltage in the background atmosphere was employed to eliminate a slow memristor effect [30-31], due to oxygen vacancy diffusion in the $\mathrm{TiO}_{2}$ layer, which the system showed in hydrogen-free atmospheres.

In the beginning of each cycle of the hydrogen sensing studies, a particular amount of $\mathrm{H}_{2}$ gas was admitted to the chamber and retained in it during $6 \mathrm{~h}$ resulting in a sharp decrease of the sample resistance. During the next $30 \mathrm{~min}$, the chamber was evacuated to 
a $10^{-6}$ Torr vacuum, followed by admission of 160 Torr oxygen retained in the chamber for $16 \mathrm{~h}$ to recover resistance of the sensor. Such a complete cycle of measurements is represented with a peak in Figure 1 plot. All the cycles reported in this paper were performed at room temperature $\left(26-28^{\circ} \mathrm{C}\right)$. Sensor resistance was recorded continuously at a rate of 5 readings per minute with a Keithley 2400 sourcemeter in the voltage source mode.

In order to understand the effect of recovery gas on the sensor performance, oxygen gas was also replaced by nitrogen, which will be discussed below. The sensor tests were conducted at different hydrogen pressures and applied voltages in the range of 0.003-3 Torr and 0.5-2.0 V, respectively.

\section{Results and Discussion}

\subsection{Sensitivity and response properties}

The variation of the $\mathrm{Pt} / \mathrm{TiO}_{2} / \mathrm{Ti}$ structure resistance with time in different concentration of hydrogen in the presence of oxygen at room temperature were studied by applying different voltages at the Pt layer relative to the Ti substrate terminal (Fig. 2). Response of the sensor to different partial pressures of $\mathrm{H}_{2}$ gas under $0.5 \mathrm{~V}$ is shown in Fig. 3(a). Upon

admission of 3 Torr of hydrogen, the initial resistance of $4.5 \cdot 10^{8} \mathrm{Ohm}$ jumped abruptly down within less than one minute, and then went more gradually down to the final value 7.5.10 $\mathrm{Ohm}$ within $6 \mathrm{~h}$. By removing $\mathrm{H}_{2}$ from the chamber during the next $30 \mathrm{~min}$ and adding pure $\mathrm{O}_{2}$ gas at 160 Torr, the sensor resistance rapidly increased to form an inverted peak; this recovery was completed by reaching into the high resistance close to the initial value within the following $16 \mathrm{~h}$. It should be noticed that the somewhat smaller resistance in pure $\mathrm{O}_{2}$ compared to the initial value is due to a shorter exposure of the sensor to the background atmosphere in between two successive additions of hydrogen gas. According to Fig. 3(a), qualitative behavior of the sensor resistance is the same for three other partial pressures of hydrogen, 0.3, 0.03 and $0.003 \mathrm{~T}$, although the lower peak value is different for each specific concentration. 
In addition, the sensor response was also measured under 1, 1.4 and $2 \mathrm{~V}$ for different concentration of $\mathrm{H}_{2}$ by the same procedure as it is explained above for $0.5 \mathrm{~V}$, see Fig. 3 . Increasing the applied voltage decreased the initial resistance of the sensor in pure oxygen. Otherwise, the sensor showed similar behaviors during the alternating exposure to hydrogen and oxygen gases. A four order of magnitude change in the resistance is typically seen due to exposure to 3 Torr of hydrogen. Also, the sensor resistance was notably decreased when it was exposed to only 0.003 Torr $\mathrm{H}_{2}$, corresponding to a concentration of $\mathrm{H}_{2}$ molecules of only $3.9 \mathrm{ppm}$ in a normal atmosphere, or $20 \mathrm{ppm}$ in the 160 Torr atmospheres used here. A solid-state sensor reacting to such small amounts of molecular hydrogen has not been reported earlier in the literature.

A formal sensitivity measure of the type

$$
S=\frac{R_{\mathrm{o} 2}-R_{\mathrm{H} 2}}{R_{\mathrm{H} 2}}
$$

was investigated. Here, $R_{\mathrm{O} 2}$ is the resistance of the sensor in the background (reference) atmosphere of pure $\mathrm{O}_{2}$ at 160 Torr, and $R_{\mathrm{H} 2}$ is the resistance in the end of the hydrogen exposure, represented by magnitudes of the inverted peaks in Fig. 3 plots. Dependences of the value $S$ on source voltage and $\mathrm{H}_{2}$ partial pressure are shown in Fig. 4. For a specific voltage, the sensitivity increases with the $\mathrm{H}_{2}$ concentration. It also increases slightly with the source voltage, except for the lowest studied hydrogen pressure $(0.003$ Torr), for which better results were observed at smaller voltages. The highest values $S$ were obtained for 3 Torr of $\mathrm{H}_{2}$, varying from 550 at $0.5 \mathrm{~V}$ to 11670 at 2V. In Fig. 4(a) it can be also noticed that the sensitivity saturates for the voltages above $1.4 \mathrm{~V}$. A sharp sensitivity drop, not shown in the figure, was observed at all hydrogen concentrations for voltages higher than $2 \mathrm{~V}$. A prolonged exposure of the sensor to such voltages may lead to an irreversible decrease of the sensitivity.

Peak resistance values on each of the Fig. 3 curves can be fitted within a $20 \%$ or better accuracy with a power function of $\mathrm{H}_{2}$ partial pressure, $p$,

$$
R(p)=a \cdot p^{b}
$$


where the parameter $b$ varies from -0.73 to -1.18 , depending on the source voltage, see Table 1.

Table 1. Value of the power function parameter $b$ in Eq. (2) for different source voltages.

\begin{tabular}{|c|r|r|r|r|}
\hline Bias (V) & 0.5 & 1.0 & 1.4 & 2.0 \\
\hline$b$-value & -0.73 & -0.96 & -1.12 & -1.18 \\
\hline
\end{tabular}

Thus, electrical conductance of the sample can be a linear response function of $\mathrm{H}_{2}$ partial pressure for a properly selected source voltage in the range 1.0-1.4 V. This provides opportunities for practical utility of the present solid-state system in hydrogen-selective pressure gauges and transducers.

\subsection{Response time}

In order to compare response time of the sensor under different voltages, the parameters $t_{20}, t_{50}$ and $t_{90}$ were defined to represent, respectively, periods of time during which the sensor resistance drops 20\%, 50\%, and 90\% from its initial value, see Figure 3. These parameters are listed in Table 2 for 3 Torr $\mathrm{H}_{2}$ exposure at different source voltages. It can be mentioned that the response time has a notable dependence on the source voltage. Upon exposure to 3 Torr of hydrogen under $1.4 \mathrm{~V}$, the sensor resistance dropped to $90 \%$ of initial value within about 4 minutes. Thus, in the view of both sensitivity (Figure 4) and response time (Table 2) data, a source voltage around $1.4 \mathrm{~V}$ is optimal for this device in hydrogen sensing applications. 
Table 2. Response time for 3 Torr $\mathrm{H}_{2}$ exposure at different source voltages.

\begin{tabular}{|c|c|c|c|}
\hline Voltage $(\mathrm{V})$ & $t_{20}(\mathrm{~s})$ & $t_{50}(\mathrm{~s})$ & $t_{90}(\mathrm{~s})$ \\
\hline 0.5 & 12 & 38 & 546 \\
\hline 1.4 & 19 & 47 & 223 \\
\hline 2.0 & 31 & 49 & 385 \\
\hline
\end{tabular}

Reviewer 2

1) "The device has a good performance on the detection of hydrogen, the detecting limitation, detecting range, response time and sensitivity of the device should be compared with the published results, for example the results of the study and previous results are listed in a Table."

Thank you for this comment. We have added the following piece with the new Table 3:

The operating conditions (temperature, hydrogen concentration, and background atmosphere), sensitivity, and response time of this and typical earlier sensors based on $\mathrm{TiO}_{2}$ are shown in Table 3. As can be seen, the present sensor device can be advantageous to the nanotube and sol-gel based sensors for its lower operating temperatures $\left(26-28^{\circ} \mathrm{C}\right)$ and a lower sensitivity threshold $(20 \mathrm{ppm})$. It also provides response times better than in the nanotube sensors, and sensitivity comparable with the sol-gel type sensors.

Table 3. Comparison of operating conditions, sensitivity, and response time of current sensor and previous sensors.

\begin{tabular}{|c|c|c|c|c|}
\hline Sensor type & Temperature $\left({ }^{\circ} \mathrm{C}\right)$ & $\mathrm{H}_{2}(\mathrm{ppm}) /$ background gas & Sensitivity & $t_{90}(\mathrm{~s})$ \\
\hline $\begin{array}{c}\text { Mesoporous anodic } \\
\mathrm{TiO}_{2}\end{array}$ & $26-28$ & $20-20000 / \mathrm{O}_{2}, \mathrm{~N}_{2}$ & $\begin{array}{c}0.35-11528 \\
(1.4 \mathrm{~V})\end{array}$ & $223-546$ \\
\hline $\begin{array}{c}\mathrm{TiO}_{2} \text { prepared by } \\
\text { sol-gel method [15] }\end{array}$ & $100-350$ & $300-10000 /$ air & $10-10000$ & $45-130$ \\
\hline $\begin{array}{c}\text { Highly ordered } \mathrm{TiO}_{2} \\
\text { nanotubes [19] }\end{array}$ & $20-150$ & $100-5000 / \mathrm{O}_{2}, \mathrm{~N}_{2}$ & $10-35$ & $\begin{array}{c}1800- \\
3900\end{array}$ \\
\hline
\end{tabular}




\subsection{Sensing mechanism}

Reviewer 1

3-4) "Fig. 5 shows the hydrogen sensing behavior in $\mathrm{O} 2$ and N2 atmospheres, the author suggested that the order of magnitude variation in the sensor resistance was similar. However, according to Fig. 5, the response time and recover time for full response/recover is much different. Can you make some explanation of this phenomenon.

Fig. 6 shows the sensing behavior in vacuum background atmoshpere. It can be found that the variation of sensitivity with the hydrogen concentration did not follow the rules shown in Fig. 5. Can you explain this phenomenon."

The following piece (blurle font below) has been amended to address these phenomena:

The mechanisms of hydrogen sensing in semiconducting catalytic systems remained unclear for a long time and different mechanisms have been introduced [16-19, 24-29]. Some studies reveled that the presence of oxygen species on the surface is necessary for the sensitivity of $\mathrm{TiO}_{2}$ based devices to hydrogen gas [24]. It has been suggested that trapping of electrons from the conduction band of a metal oxide semiconductor by adsorbed oxygen molecules and return of these electrons to the conduction band by a reducing gas $\left(\mathrm{H}_{2}\right)$ are responsible for the hydrogen sensitivity [25]. In a quest for information about the correct sensing mechanism, the effect of background atmosphere type and source voltage polarity on the performance of present hydrogen sensor was investigated. The response of the sensor to different concentrations of $\mathrm{H}_{2}$ under $1 \mathrm{~V}$ in 160 Torr $\mathrm{O}_{2}$ and $\mathrm{N}_{2}$ backgrounds is shown in Fig. 5. In contrast to the redox mechanism [24-25], by comparing the $\mathrm{O}_{2}$ and $\mathrm{N}_{2}$ curves shown in Fig. 5, it can be concluded that the presence of oxygen molecules was not an essential factor for the hydrogen sensing measurements. On the contrary, the initial resistance, recovery values and flatness of the curves (at 0.3 and 3 Torr $\mathrm{H}_{2}$ ) were higher for the $\mathrm{O}_{2}$ atmosphere. This fact could be explained by partial blockage of the active sensor surface with products of a slow oxyhydrogen reaction (water and $\mathrm{OH}$ radicals). These authors earlier showed that the oxyhydrogen reaction can be initiated on a similar catalytic surface at 16 Torr $\mathrm{H}_{2}$ even at room temperature [22-23]. On the other hand, the order of magnitude variation in the sensor resistance in Fig. 5 data was similar for the two background gases at all $\mathrm{H}_{2}$ partial pressures.

Fig. 6 shows variation of the sensor resistance versus time for a high vacuum background $\left(10^{-7}\right.$ Torr) under the voltage $1 \mathrm{~V}$. It can be seen that the sensor responded to and 
recovered from all the different concentrations of $\mathrm{H}_{2}$ approximately at the same order of magnitude variation. This result provides further evidence toward the slow oxyhydrogen reaction hypothesis of the previous paragraph, because in this experiment the sensor surface remains free of any compound molecules of radicals at all times. Thus, the background gas $\left(\mathrm{O}_{2}\right.$ or $\left.\mathrm{N}_{2}\right)$ only diminishes the sensor response, especially at the lower $\mathrm{H}_{2}$ concentrations. Furthermore, independence of the response on the gas type, Fig. 5, suggests that molecules of the background gas participate only in physisorption processes on the sensor surface.

Recent studies show different mechanisms in which the hydrogen molecules dissociate and form atomic hydrogen on the metal surface. These hydrogen atoms will then diffuse through the metal and precipitate at the metal/semiconductor interface, decreasing the metal work function, and therefore reducing the Schottky barrier height $[18,26]$. Fig. 7 shows the sensor responses when it was exposed to 3 Torr of hydrogen in high vacuum $\left(10^{-7}\right.$ Torr) under +1.4 and $-1.4 \mathrm{~V}$ at room temperature. It can be seen that the order of magnitude variation in the sensor resistance under the positive source voltage is noticeably greater compared to the response at the negative voltage. This result indicates that the barrier reduction mechanisms based on electronic conductance is not fully applicable to the present sensor type. We suggest that ionic transport in $\mathrm{TiO}_{2}$ serving as a solid electrolyte, also plays an important role in the sensing performance reported here. In particular, hydrogen ions $\left(\mathrm{H}^{+}\right)$generated on the $\mathrm{Pt}$ nanomesh under positive bias in the presence of hydrogen adsorbate species are drifting toward the back Ti contact of the sensor to recombine there with electrons arriving from the external circuit, Fig. 2. A negatively biased catalytic electrode, on the contrary, cannot produce a significant amount of hydrogen ions, and therefore the sensor response was minute at the negative source voltage. It is also possible that the mechanism of oxygen vacancy $\left(V_{\mathrm{O}}\right)$ drift in $\mathrm{TiO}_{2-x}$ areas under electrical potential [30-31] is intertwined with the $\mathrm{H}^{+}$diffusion process in the present sensor type. 


\section{Conclusion}

The transient response of a $\mathrm{Pt} / \mathrm{TiO}_{2} / \mathrm{Ti}$ sensor based on anodically grown mesoporous titania was studied at room temperature for different hydrogen concentrations and applied source voltages, and in three different background (reference) atmospheres: 160 Torr $\mathrm{O}_{2}$, 160 Torr $\mathrm{N}_{2}$, and $10^{-7}$ Torr vacuum. Comparable results were obtained in these atmospheres to reveal that the response of the sensor is not influenced by adsorbed $\mathrm{O}^{-}$ species [24], and the background gas molecules are likely to participate only in physisorption processes on the sensor surface. The applied source voltage in the range of $0.5-2 \mathrm{~V}$ had a great effect on the sensor sensitivity with the highest sensitivity observed at $1.4 \mathrm{~V}$. For the 0.03-3 Torr $\mathrm{H}_{2}$ exposures, the sensitivity increased with the source voltage until $1.4 \mathrm{~V}$ and then saturated at about $2 \mathrm{~V}$. Irreversible changes of the sensor behavior occurred for voltages higher than $2 \mathrm{~V}$, at which the sensitivity decreased significantly. For a source voltage in the range 1.0-1.4 V, electrical conductance of the sensor can be a linear response function of the $\mathrm{H}_{2}$ partial pressure. The obtained data suggests that ionic conductance and vacancy diffusion processes in the mesoporous titania contributes to the resistive response of the sensor during hydrogen exposure.

\section{Acknowledgements}

This research was supported by National Science Foundation via grant \#1033290, and by the Center for Nanoscale Materials at Argonne National Laboratory. Use of the Center for Nanoscale Materials was supported by the U.S. Department of Energy, Office of Science, Office of Basic Energy Sciences, under Contract \#DE-AC02-06CH11357.

\section{References}

[1] T. Hübert, L. Boon-Brett, G. Black, U. Banach, Hydrogen sensors-A review, Sensors and Actuators B, 157, 329-352, 2011. 
[2] N. Maffei, A.K. Kuriakose, A solid-state potentiometric sensor for hydrogen detection in air, Sensors and Actuators B, 98, 73-76, 2004.

[3] D. Zalvidea, A. Díez, J.L. Cruz, M.V. Andrés, Hydrogen sensor based on a palladium-coated fibre-taper with improved time response, Sensors and Actuators B, 114, 268-274, 2006.

[4] S.Y. Chiu, J.H. Tsai, H.W. Huang, K.C. Liang, T.H. Huang, K.P. Liu, T.M. Tsai, K.Y. Hsu, W.S. Lour, Hydrogen sensors with double dipole layers using a Pd-mixture-Pd triple-layer sensing structure, Sensors and Actuators B, 141, 532-537, 2009.

[5] F. Rumiche, H.H.Wang, W.S. Hu, J.E. Indacochea, M.L.Wang, Anodized aluminum oxide (AAO) nanowell sensors for hydrogen detection, Sensors and Actuators B, 134, 869-877, 2008.

[6] I.I. Nedrygailov, E.G. Karpov, Pd/n-SiC nanofilm sensor for molecular hydrogen detection in oxygen atmosphere, Sensors and Actuators B, 148, 388-391, 2010.

[7] P. Fedtke, M. Wienecke, M.C. Bunescu, M. Pietrzak, K. Deistung, E. Borchardt, Hydrogen sensor based on optical and electrical switching, Sensors and Actuators B, 100, 151-157, 2004.

[8] J.R Huang, W.Ch Hsu, H.I Chen, W.Ch Liu, Comparative study of hydrogen sensing characteristics of a $\mathrm{Pd} / \mathrm{GaN}$ Schottky diode in air and N2 atmospheres, Sensors and Actuators B, 123, 1040-1048, 2007.

[9] J. Song, W. Lu, J.S. Flynn, G.R. Brandes, AlGaN/GaN Schottky diode hydrogen sensor performance at high temperatures with different catalytic metals, Solid-State Electronics, 49, 1330-1334, 2005.

[10] K. Zdansky, R. Yatskiv, Schottky barriers on InP and GaN made by deposition of colloidal graphite and $\mathrm{Pd}, \mathrm{Pt}$ or bimetal $\mathrm{Pd} / \mathrm{Pt}$ nanoparticles for $\mathrm{H}_{2}$-gas detection, Sensors and Actuators B, 165, 104-109, 2012.

[11] F.K. Yam, Z. Hassan, Schottky diode based on porous $\mathrm{GaN}$ for hydrogen gas sensing application, Applied Surface Science, 253, 9525-9528, 2007. 
[12] B.P. Luther, S.D. Wolter, S.E. Mohney, High temperature Pt Schottky diode gas sensors on n-type GaN, Sensors and Actuators B, 56, 164-168, 1999.

[13] T.H Tsai, J.R. Huang, K.W Lin, W.Ch Hsu, H.I Chen, W.C Liu, Improved hydrogen sensing characteristics of a Pt/SiO2/GaN Schottky diode, Sensors and Actuators B, 129, 292-302, 2008.

[14] K. Chen, K. Xie, X. Feng, S. Wang, R. Hu, H. Gu, Y. Li, An excellent roomtemperature hydrogen sensor based on titania nanotube-arrays, international journal of hydrogen energy, 37, 13602-13609, 2012.

[15] A.A Haidry, J. Puskelova , T. Plecenik , P. Durina , J. Gregus , M. Truchly ,T. Roch, M. Zahoran, M. Vargova, P. Kus, A. Plecenik, G. Plesch, Characterization and hydrogen gas sensing properties of $\mathrm{TiO}_{2}$ thin films preparedby sol-gel method, Applied Surface Science, 259, 270-275, 2012.

[16] J. Moon, M. Kemell, J. Kukkola, R. Punkkinen, H.P. Hedman, A.Suominen, E. Mäkilä, M. Tenho, A. Tuominen, H. Kim, Gas sensor using anodic $\mathrm{TiO}_{2}$ thin film for monitoring hydrogen, Procedia Engineering, 47, 791-794, 2012.

[17] S. Rahbarpour, S.M. Hosseini-Golgoo, Diode type $\mathrm{Ag}-\mathrm{TiO}_{2}$ hydrogen sensors, Sensors and Actuators B: Chemical, 187, 262-266, 2013.

[18] Y. Shimizu, T. Hyodo, M. Egashira, $\mathrm{H}_{2}$ sensing performance of anodically oxidized $\mathrm{TiO}_{2}$ thin films equipped with Pd electrode, Sensors and Actuators B, 121, 219-230, 2007.

[19] E. Şennik, Z. Çolak, N. Kılınç, Z. Z. Öztürk, Synthesis of highly-ordered $\mathrm{TiO}_{2}$ nanotubes for a hydrogen sensor, international journal of hydrogen energy, 35, 44204427, 2010.

[20] O.K. Varghese, D. Gong, M. Paulose, K.G. Ong, E.C. Dickey, C.A. Grimes, Extreme Changes in the Electrical Resistance of Titania Nanotubes with Hydrogen Exposure, Advanced Materials, 15, 624-627, 2003.

[21] A.Ali Haidry, P. Schlosser, P. Durina, M. Mikula, M. Tomasek, T. Plecenik, T. Roch, A. Pidik, M. Stefecka1, J. Noskovic1,M. Zahoran, P. Kus, A. Plecenik, Hydrogen 
gas sensors based on a nocrystalline $\mathrm{TiO}_{2}$ thin films, Cent. Eur. J. Phys, 9, 1351-1356, 2011.

[22] E.G. Karpov, M.A. Hashemian, S.K. Dasari, Chemistry-Driven Signal Transduction in a Mesoporous Pt/TiO2 System. J. P. Chem. C, 117, 15632-15638, 2013.

[23] M.A. Hashemian, E. Palacios, I.I. Nedrygailov, D. Diesing, E.G. Karpov. Thermal Properties of the Stationary Current in Mesoporous Pt/TiO2 Structures in Oxyhydrogen Atmosphere. ACS Applied Materials and Interfaces 5(23), 12375-12379, 2013.

[24] Bates JB, Wang JC, and Perkins RA, Mechanisms for hydrogen diffusion in $\mathrm{TiO}_{2}$, Phys. Rev. B, 19, 4130-9, 1979.

[25] C. Wang, L.Yin , L. Zhang, D. Xiang, R. Gao, Metal Oxide Gas Sensors: Sensitivity and Influencing Factors, Sensors, 10, 2088-2106, 2010.

[26] S. Roy, C. Jacob, S. Basu, Studies on Pd/3C-SiC Schottky junction hydrogen sensors at high temperature, Sensors and Actuators B, 94, 298-303, 2003.

[27] L.A. Harris, A Titanium Dioxide Hydrogen Detector, J. Electrochem Soc, 127, 2657-2662, 1980.

[28] K. Zakrzewska, Titanium Dioxide Thin Films for Gas Sensors and Photonic Applications, Advances in Materials Science and Engineering, 2012, 13 pages, 2012.

[29] Y.-K. Jun, H.-S. Kim, J.-H. Lee, S.-H. Hong, High H2 sensing behavior of TiO2 films formed by thermal oxidation, Sensors and Actuators B, 107, 264-270, 2005.

[30] J. Wu, R. L. McCreery, Solid-State Electrochemistry in Molecule/TiO2 Molecular Heterojunctions as the Basis of the TiO2 "Memristor", Journal of The Electrochemical Society, 156, 29-37, 2009.

[31] K. Miller, K.S. Nalwa, A. Bergerud, N.M. Neihart, Member, S. Chaudhary, Memristive Behavior in Thin Anodic Titania, IEEE Electron Device Lett, 31, 737-739, 2010. 
Figures (with captions)

a)
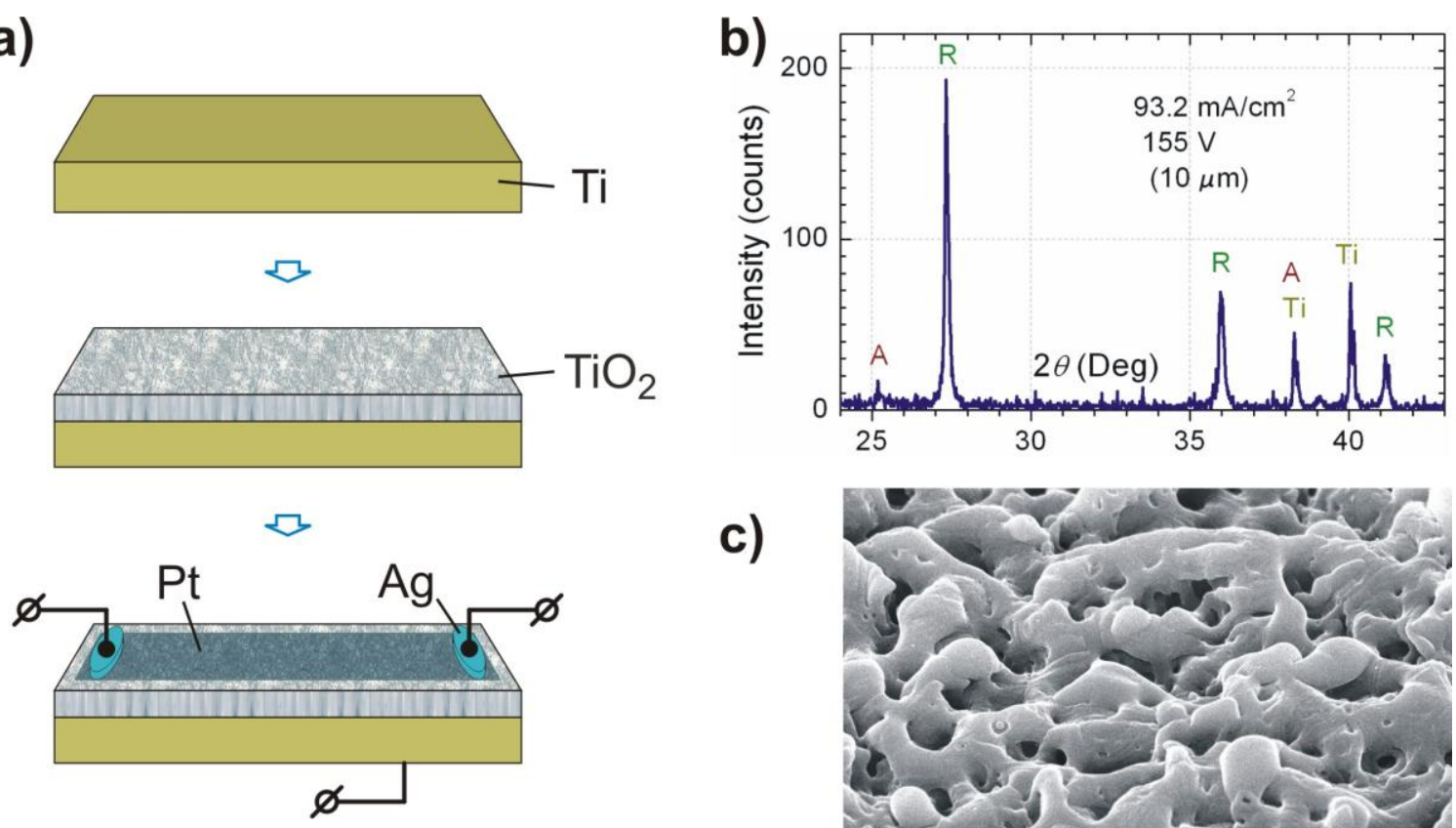

c)

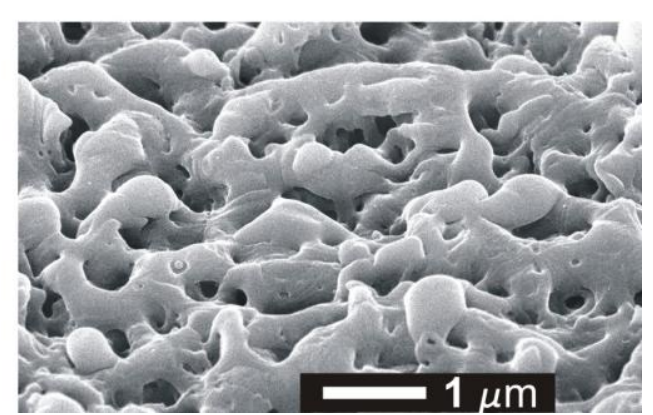

Fig. 1: (a) Sample fabrications steps, (b) XRD analysis of the mesoporous $\mathrm{TiO}_{2}$ layer, and (c) and FE SEM scan (at viewing angle $45^{\circ}$ ) of the Pt-coated $\mathrm{TiO}_{2}$ surface. 


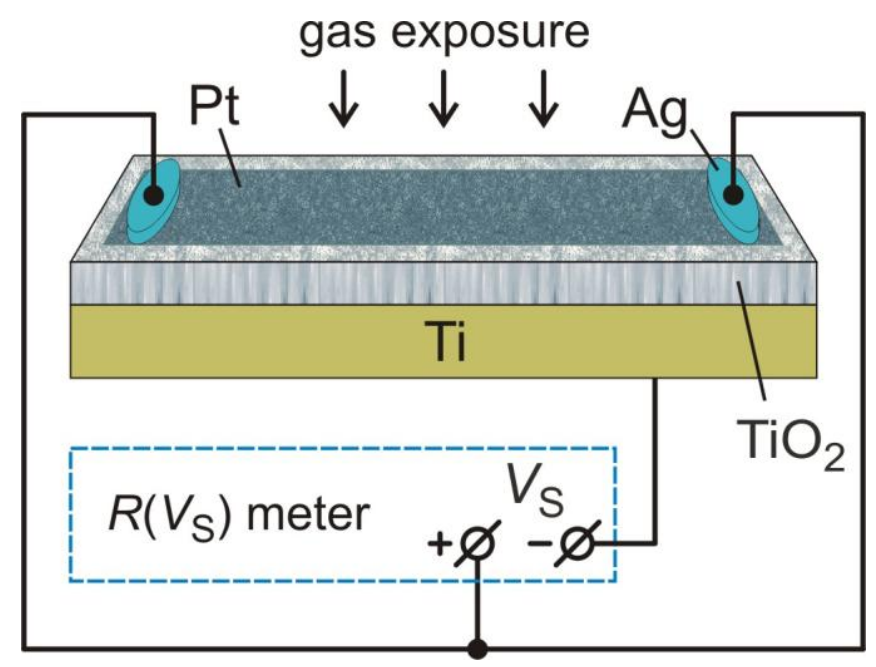

Fig. 2: Sample wiring and the setup for resistance $(R)$ measurements; $V_{\mathrm{S}}$ is a fixed source voltage. 


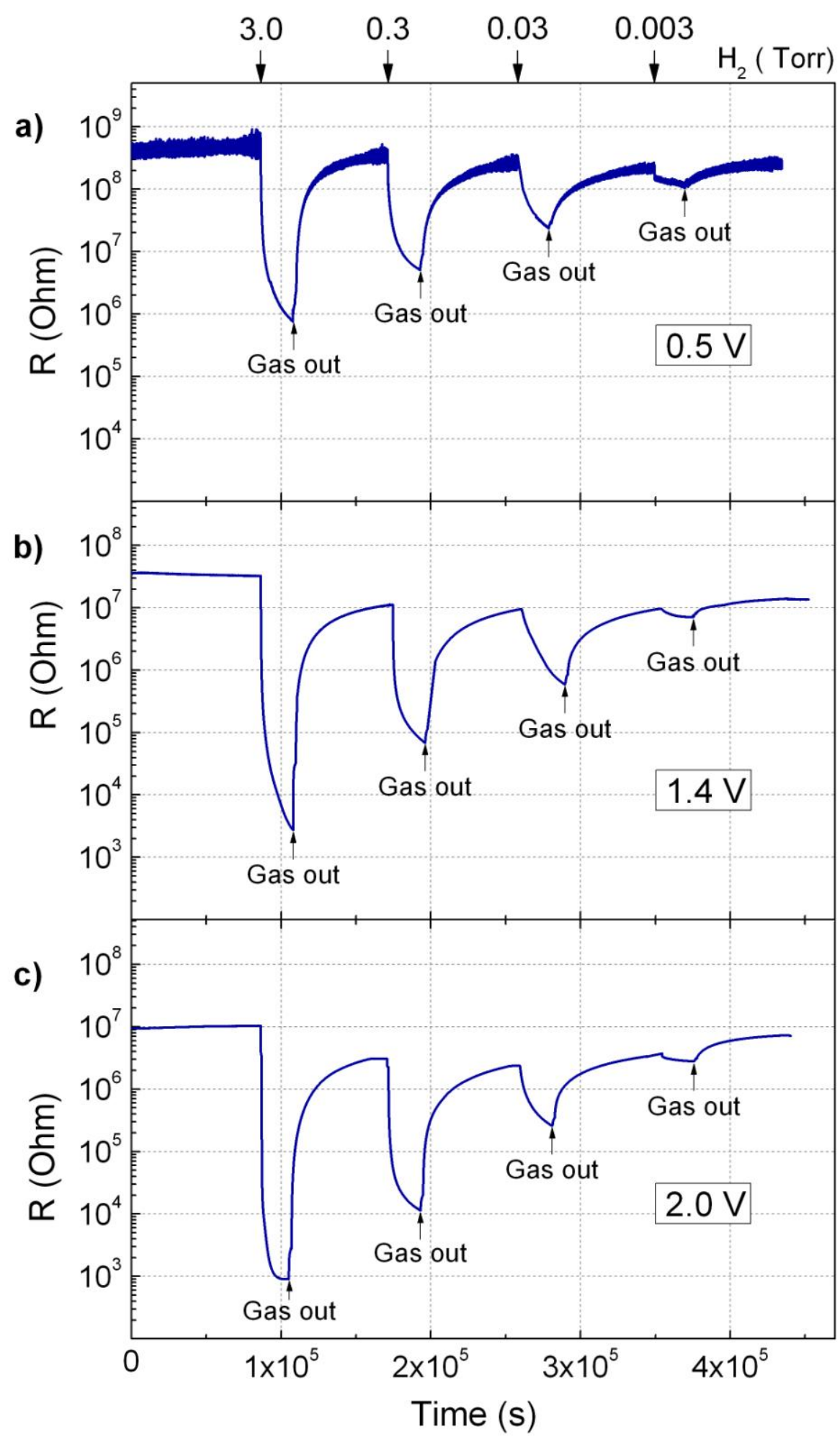

Fig.3: Response transients of the mesoporous $\mathrm{Pt} / \mathrm{TiO}_{2}$ hydrogen sensor in the background atmospheres of 160 Torr oxygen at various source voltages: (a) $0.5 \mathrm{~V}$ (a), (b) $1.4 \mathrm{~V}$ (b), and (c) $2 \mathrm{~V}$. 

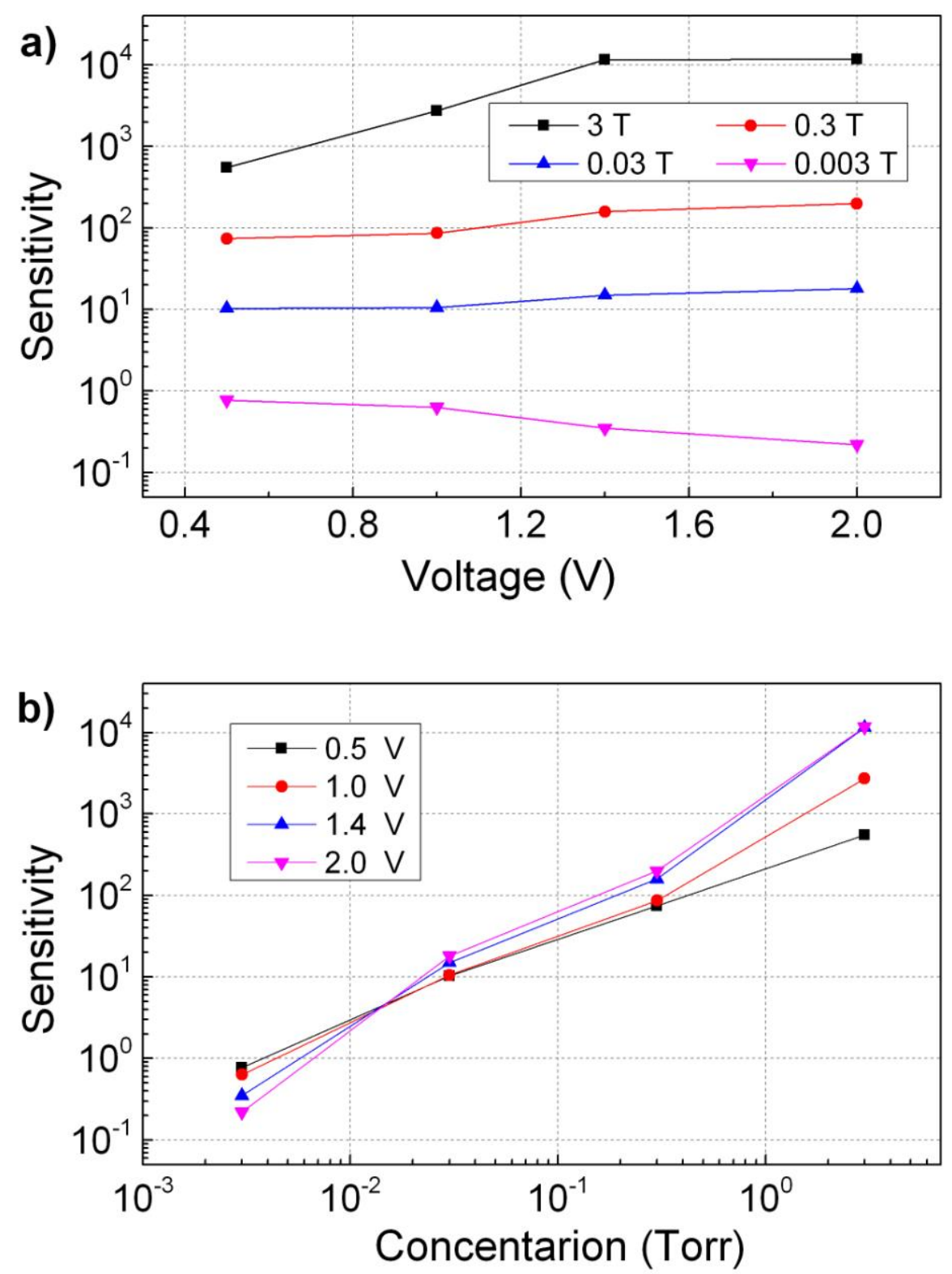

Fig.4: Sensitivity of the sensor versus voltage (a) and concentration of hydrogen (b) based on Fig. 3 data. 


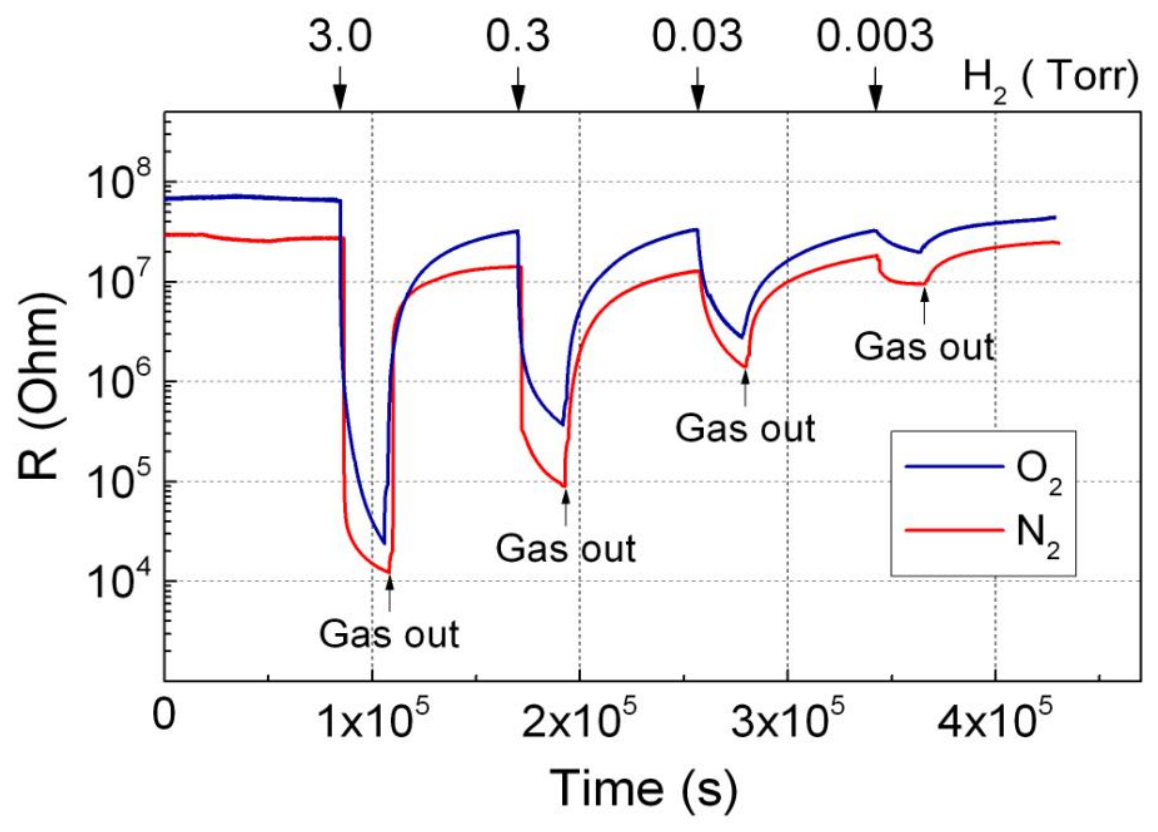

Fig.5: Comparative behavior of the sensor in the background atmospheres of 160 Torr oxygen and nitrogen under source voltage $1 \mathrm{~V}$. 


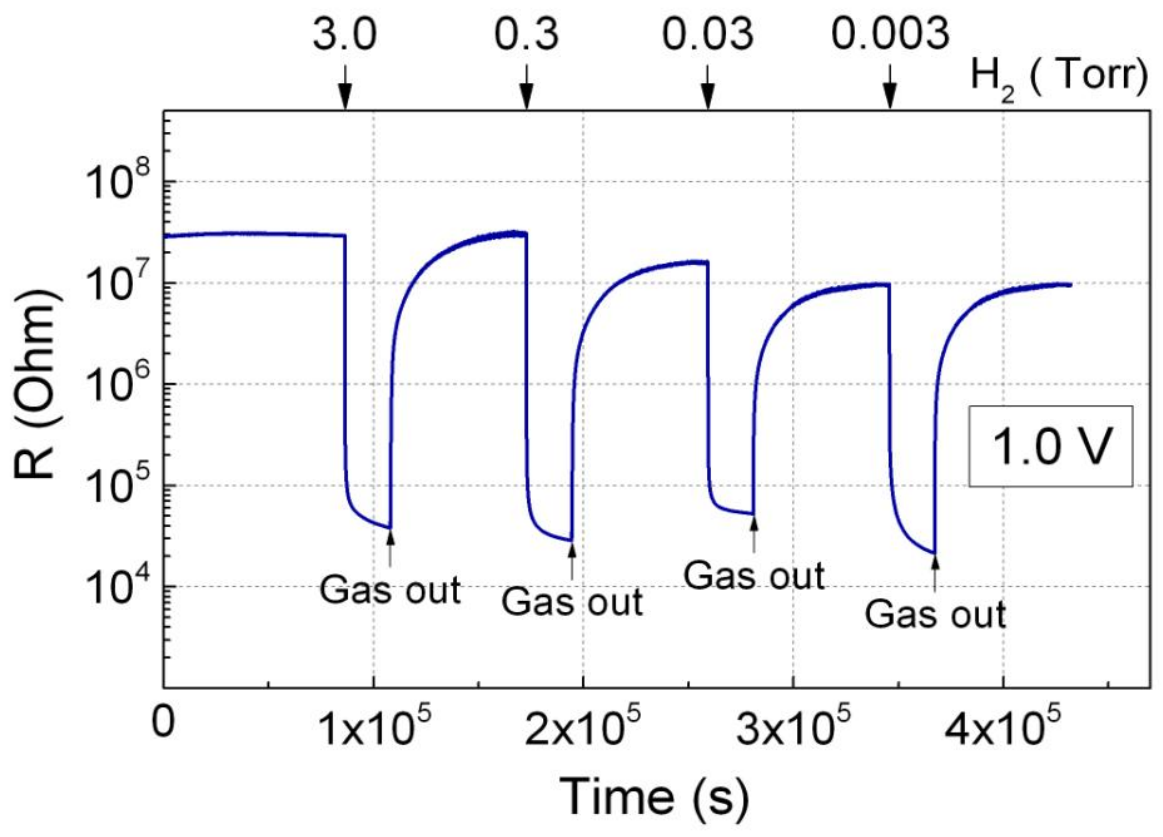

Fig.6: Sensor resistance variations in $10^{-7}$ Torr vacuum background for different concentrations of $\mathrm{H}_{2}$ under source voltage $1 \mathrm{~V}$. 


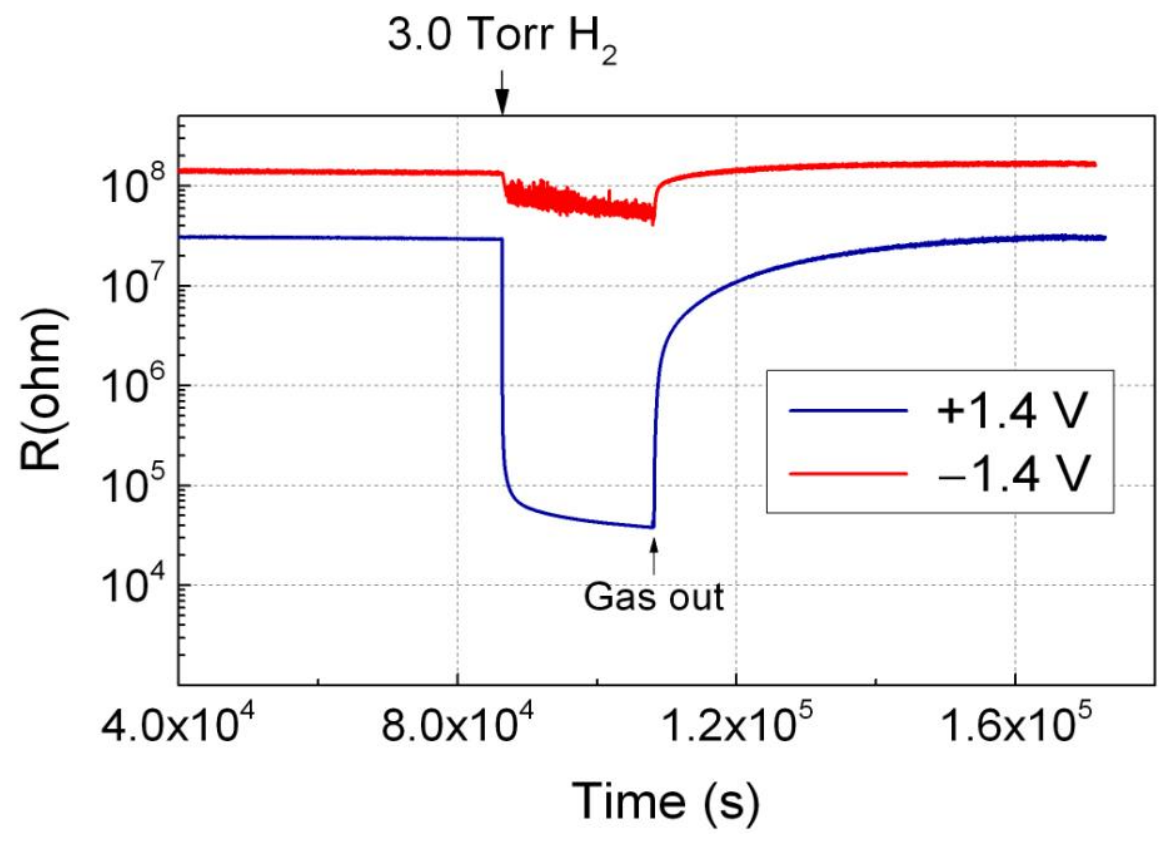

Fig.7: The variation of sensor resistance versus time in high vacuum $\left(10^{-7}\right.$ Torr $)$ for 3 Torr of $\mathrm{H}_{2}$ under source voltages +1.4 and $-1.4 \mathrm{~V}$. 